\title{
Preterm Prematür Membran Rüptürü Olgularında Spontan ve İndüklenmiş Eylemin Maternal ve Fetal Sonuçlara Etkisi
}

\author{
The Influence of Spontaneous and Induced Labor in Maternal and Fetal Outcomes in \\ Preterm Premature Rupture of Membranes
}

\section{Gürcan TÜRKYILMAZ ${ }^{1}$, Şebnem Erol TÜRKYILMAZ ${ }^{2}$ Mesut POLAT $^{1}$, Enis ÖZKAYA ${ }^{3}$, Murat API ${ }^{3}$}

\author{
1. İstanbul Üniversitesi İstanbul Tip Fakültesi, Kadın Hastalıkları ve Doğum Anabilim Dalı, İstanbul, Türkiye \\ 2. İstanbul Eğitim Araştırma Hastanesi, Kadın Hastalıkları ve Doğum Kliniği, İstanbul, Türkiye \\ 3. Zeynep Kamil Kadın ve Çocuk Hastalıkları Eğitim Arş. Hastanesi, Kadın Hastalıkları ve Doğum Kliniği, İstanbul, Türkiye
}

$\ddot{O Z E T}$

Amaç: Bu çalışmamızda preterm prematür membran rüptürü (PPROM) ile komplike gebeliklerde spontan travaya giren olgularla çeşitli endikasyonlarla doğum indüksiyonu yapılan olguların perinatal sonuçlarını ve latent sürenin bu sonuçlara etkisini araştırmayı amaçladık.

Gereçler ve Yöntem: Ocak 2014-Ocak 2016 yillart arasında kliniğimizde 24-34 gebelik haftalar arasindaki PPROM tanisl alan gebelerin perinatal sonuçları retrospektif olarak değerlendirildi.

Bulgular: Çalışmaya 93 olgu dahil edildi ve 43 olguda (\%46) doğum eylemi takip sirasinda spontan başladı (Grup 1), 50 olguda (\%54) ise doğum eylemi indüksiyonla bașlatıld (Grup 2). PPROM oluşan zamandan doğuma kadar geçen süre Grup

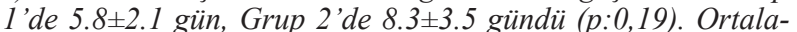
ma doğum haftası Grup 1'de 30.4 \pm 2.3 hafta iken Grup 2'de $30.5 \pm 2.5$ haftaydı (p: 0.91). Doğum ăgırlıkları arasında anlaml fark saptanmadl. Grup l'de 19 (\%44.1) olgu sezaryen ile doğum yaptı, Grup 2'de ise 37 (\%74) olguda sezaryen ihtiyact görüldü (p:0.03). Grup 1'de 4 (\%9.3), grup2'de 3 (\%6) olguda YDYBÜ takibi sirasında exitus gerçekleşti (p: 0.54). Grup 1 'de 14 (\%32.5) Grup 2'de ise 17 (\%34) olguda ciddi morbidite geliştiği görüldü. Mortalite ve ciddi morbidite üzerine latent sürenin anlaml etkisi görülmedi (p:0.54, p:0.67).

Sonuç: PPROM olgularında latent sürenin neonatal sonuçlara anlaml etkisi gösterilmemiştir ve maternal veya fetal iyilik hali güven verdiği sürece ekspektan yaklaşım uygun takip yöntemidir.

Anahtar Kelimeler: eylem, erken doğum, yenidoğan

\section{ABSTRACT}

Objective: We evaluated the effect of spontaneous and induced parturition in maternal and fetal outcomes in preterm prematüre rupture of membranes (PPROM) and analyzed the influence of the latent period in these results.

Material and Methods: We analyzed the results of patients who were complicated with PPROM in 24-34 weeks of gestation between January 2014-January 2016 in our clinic.

\section{İletişim}

Sorumlu Yazar: Gürcan TÜRKYILMAZ

Adres: İstanbul Üniversitesi, İstanbul Tıp Fakültesi, Kadın Hastalıkları ve Doğum Anabilim Dalı, İstanbul, Türkiye

Tel: +90 (212) 4142000

E-Posta: gurcanturkyilmaz@gmail.com

Makale Geliş: 17.03.2019

Makale Kabul: 10.05.2019

DOI: http://dx.doi.org/10.16948/zktipb.541187
Results: We collected 93 cases and in 43 patients (46\%) the labor occurs spontaneously (Group 1) and in 50 cases (54\%) we induced the labor due to maternal and fetal indications (Group 2). The interval between when PPROM occurred, and labor was $5.8 \pm 2.1$ days in group 1 and $8.3 \pm 3.5$ days in group 2 ( $p: 0,19)$. There was no significant difference between birthweights in two groups. C-section was performed in 19 (\%44.1) patients in group 1 and $37(\% 74)$ cases were delivered by $C$-section in group 2 (p: 0.03). Neonatal mortality was $9.3 \%$ in group 1 and $6 \%$ in group 2 (p:0.54). Severe morbidity was detected in $14(\% 32.5)$ patients in group 1 and $17(\% 34)$ in group 2 . We did not show a significant effect of latency period into the severe morbidity and mortality in newborns (p:0.54, p:0.67).

Conclusion: There was no relevant effect of latency period into the neonatal outcomes, and expectant management should be used in PPROM cases if the maternal and fetal status is reassuring.

Keywords: newborn, parturition, premature birth

\section{GİRIŞ}

Doğum eyleminden ve 37. haftadan önce amniyotik membranların rüptüre olması olarak tanımlanan preterm erken membran rüptürü (PPROM) tüm gebeliklerin $\% 3$ 'ünde görülür ve preterm doğumların yaklaşık \%30-35'den sorumludur (1).

Preterm eylem sonucu doğan bebeklere ait mortalite oranı konjenital anomaliler dişlandığında, perinatal ölümlerin \%85'ini oluşturmaktadır ve mortalite oranları doğum ağırlığ1 ve gestasyonel yaş azaldıkça artar $(2,3)$. Hayatta kalan olgularda ise respiratuar distres sendomu (RDS), bronkopulmoner displazi (BPD), intraventriküler hemoraji (IVH), patent duktus arteriozus (PDA), nekrozitan enterokolit (NEK), prematüre retinopatisi, neonatal sepsis ve hiperbilirubinemi gibi bir çok kısa ve uzun dönem komplikasyon riski mevcuttur. PPROM'un kesin nedeni bilinmemesine rağmen olguların büyük bir çoğunluğunda, özellikle erken haftalarda intraamniyotik enfeksiyonlar başlica neden gibi görülmektedir (4). Daha önceki gebeliklerde PPROM öyküsü olması, antepartum kanama, genital enfeksiyon varlığı, sigara kullanımı, ikinci tirmesterde kısa serviks saptanması PPROM etiyolojisinde en önemli risk faktörleridir. İleri anne yaş1, düşük sosyoekonomik düzey, prenatal bakımın yetersizliği, anemi, servikal cerrahi öyküsü, uterin anomaliler, çoğul gebelikler, polihidramniyos, kolajen doku hastaliklar1, plasenta previa, dekolman plasenta, periodontal hastalıklar, üriner ve diğer sistem enfeksiyonları 
ise PPROM ile ilişkili olduğu düşünülen diğer risk faktörleridir (5, 6). Ancak PPROM olgularının çoğu risk faktörü olmaksızın meydana gelir. Membranın yırtılması ve doğumun başlaması arasında latent bir devre vardır ve bu süre gebelik haftası ne kadar küçükse o kadar uzun olma eğilimindedir (7). PPROM olgularının yönetiminde eğer koryoamniyonit veya fetal distress gibi bir komplikasyon gelişmezse genellikle 34. Gebelik haftasına kadar yakın takip önerilir (8). Bu çalışmada kliniğimizde 2014-2016 yılları arasında 24-34 gebelik haftaları arası PPROM nedeniyle takip edilen olgularda spontan eylem ve indüklenmiş eylemin maternal ve fetal sonuçlarının retrospektif olarak karşılaştırıldık ayrıca latent sürenin maternal ve yenidoğan dönemi mortalitesi ve morbiditesi üzerinde etkisini araştırdık.

\section{GEREÇ ve YÖNTEM}

Ocak 2014-Ocak 2016 yılları arasında kliniğimizde 24-34 gebelik haftalarında olup PPROM tanis1 alan gebeler retrospektif olarak değerlendirmeye alındı. Çalışma öncesi hastane etik kurul komitesinden etik kurul onayı alınd1. Spekulum muayenesinde serviksten aktif amniyotik sıvı kaçış1 gözlenmesi durumunda PPROM tanısı koyuldu. PPROM tanısı doğrulanmış olan bu olgular içerisinden fetal anomalisi olanlar, servikal yetmezlik tan1sı olanlar, saptanmış uterin anomalisi olanlar, çoğul gebelikler, daha önce sezaryen veya uterin cerrahi geçirmiş olgular, doğum kararını etkileyecek fetal ve maternal ek hastalığ yer almak istemeyen olgular çalışma dişında bırakıldı. Tüm olgulardan çalışma öncesi aydınlatılmış yazılı onam alındi.

Çalışmamızda çalışmaya dahil edilme kriterlerine uyan tüm olgulara aynı klinik takip ve tedavi uygulandı. Bütün olgularda maternal-fetal enfeksiyon varlığ 1 ve fetal iyilik hali değerlendirildikten sonra acil doğum gerekliliği olmayan (koryoamnionit, fetal distres, dekolman şüphesi, kord prolapsusu gibi) olgular takibe alındı. Çalışmaya toplamda 93 olgu dahil edildi. Takip süresinde spontan travaya giren olgular Grup 1, maternal veya fetal endikasyonla doğum indüksiyonu başlananlar veya 34 . Gebelik haftasına ulaşıp doğum indüksiyonu kararı verilen olgular Grup 2 olarak siniflandirildı. Doğum indüksiyonu endikasyonlarımız; fetal distres, koryoamnionit, dekolman plasenta, anhidroamnioz ve gebeliğin 34 . haftaya ulaşmış olmasıydı. Bu endikasyonların mevcut olduğu tüm olgularda doğum indüksiyonu yapıldı ve bunun sonucunda doğum gerçekleşti. Bu endikasyonlar saptanmayan hiçbir olguda doğum indüksiyonu yapılmadı ve olgularda, takibe devam edilen süre içerisinde spontan eylemin başlaması sonucu doğum gerçekleşti.

Takipler sırasında maternal ateş en az iki kez 38 derece ve üzerine çıkarsa ve buna eşlik eden lökositoz $(>15.000 / \mathrm{ml})$, maternal taşikardi $(>100 / \mathrm{dk})$, fetal taşikardi $(>160 / \mathrm{dk})$ veya uterin hassasiyet ve kötü kokulu vajinal akıntı varlığında koryoamniyonit tanısı koyuldu ve bu olgularda hemen doğum gerçekleştirildi.

Tüm olgulara antibiyoterapi başland1 ve tek kür kortikosteroid (24 saat arayla $12 \mathrm{mg}$ betameta- zon) uygulanması planlandı. 10 gün ampisilin 1 gr $4 \times 1$ IV. ve tedavinin ilk 3 gününde beraberinde azitromisin 500mg 1x1 tablet oral yolla verildi. Olgular klinik koryoamnionit gelişimi açısından günlük ateş ve nabız, iki günde bir lökosit değerleri ölçülerek takibe alınd. Fetal iyilik hali değerlendirmesi ise, 24-27 hafta arası olgular günlük Amniyotik sıv1 indeksi (ASI) ölçümü ve fetal kardiyak aktivite tayini ile 27-34 hafta arası olgular günlük ASİ ölçümü ve Non stress test (NST)ile yapıldi.

Kliniğimizde bu hastalar için uygulanan tedavi protokolleri ve süreleri dişına çıkılmadan her olgu uygun maternal ve fetal iyilik testleri ile takip edildi. Bu süre içinde maternal ve fetal iyilik hali parametreleri kaydedildi. Doğum haftası ve doğum şekli, doğum gerçekleştikten sonra yenidoğanların yoğun bakım ünitesi ihtiyacı olup olmadığı, eğer ihtiyacı olduysa kaç gün süreyle olduğu ve bu dönemde yenidoğandan döneminde oluşan ciddi morbidite ve prognozları her iki Grup arasında karşılaştırıldı.

Yeni doğan yoğun bakım ünitesi (YDYBÜ) yatış1 sırasında gerçekleşen menenjit, nekrotizan enterokolit (NEK), pnömoni, pnömotoraks, intrakraniak hemoraji (IKH) komplikasyonlarından biri veya birkaçının görülmesi ciddi morbidite olarak tanımland1.

İstatiksel analizler SPSS (Statistical Package for Social Sciences, version 17.0) programı kullan1larak yapıldı. Analizde T-Test ve Chi-Squared testi kullanıldı. Tüm testler için $\mathrm{p}<0,05$ olan değerler istatistiksel olarak anlamlı kabul edildi.

\section{BULGULAR}

Çalışmaya 93 olgu dahil edildi ve 43 olguda (\%46) doğum eylemi takip sırasında spontan başlad1 (Grup 1), 50 olguda (\%54) ise doğum eylemi indüksiyonla başlatıldı (Grup 2). Grup 1'de ortalama maternal yaş $29.4 \pm 5.6$, Grup 2 'de ise $30.7 \pm 6.3$ yıl, Grup 1'de ortalama vücut kitle indeksi 28.1 \pm 5.3 , Grup 2'de ise $29.1 \pm 4.7 \mathrm{~kg} / \mathrm{m} 2$ olarak bulundu ve aralarında istatistiksel olarak anlamlı bir fark bulunmadi. Grup 1'deki hastaların 20(\%42.5)'si nullipar 23(\%57.5)'ü multiparken, Grup 2'de 35 (\%66) multipar 15 (\%34) nullipar hasta mevcuttu. PPROM'un

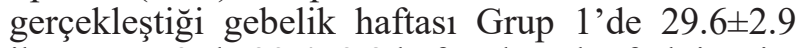
iken Grup 2'de 29.4 2 .8 haftayd 1 ve bu fark istatistiksel olarak anlamlı değildi (p: 0.75)

Sigara kullanımı sorgulandığında Grup 1'deki hastaların $4(\% 9.3)$ 'ü gebeliğinde sigara içtiğini ifade ederken Grup 2' deki olguların 6(\%11.3)'sı sigara kullanıyordu ve gruplar arasında anlamlı fark bulunmad1 (p: 0.33). Olgular daha önceki gebeliklerinde PPROM öyküsü varlığı açısından kıyaslandığında Grup 1'de hiçbir olguda PPROM öyküsü yokken, Grup 2'de 1 olguda PPROM öyküsü mevcuttu ve bu fark anlamlı bulunmadı (p: 0,35). Hastaneye yatışta ölçülen amniyon mayi değerlerinde ve yatış süresindeki ortalama maternal lökosit sayısında anlamlı fark bulunmadı (sırasılyla p:0,76 ve p: 0.46). Yatıştan doğuma kadar ortalama antibiyoterapi süresi

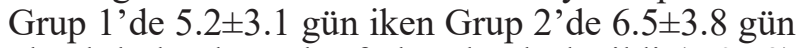
olarak bulundu ve bu fark anlamlı değildi (p:0.73) ve bir kür kortikosteroid uygulaması tamamland1ktan sonra doğuma kadar geçen sürelerin ortalama- 
ları karşılaştırıldığında iki Grup arasında anlamlı fark izlenmedi (p:0,32). Grupların doğum öncesi ve doğum sonrası bulguları Tablo-1 ve Tablo-2'de özetlenmiștir.

Tablo 1: Grupların doğum öncesi klinik bulgularının karşılaştırılması.

\begin{tabular}{|l|l|l|l|}
\hline \multicolumn{1}{|c|}{ Değişken } & \multicolumn{1}{|c|}{$\begin{array}{c}\text { Grup 1 } \\
(\mathrm{N}: 43)\end{array}$} & $\begin{array}{r}\text { Grup 2 } \\
(\mathrm{N}: 50)\end{array}$ & $\mathrm{p}$ \\
\hline Yaş (yıl) & $29.4 \pm 5.6$ & $30.7 \pm 6.3$ & 0.29 \\
\hline VKİ (kg/m²) & $28.1 \pm 5.3$ & $29.3 \pm 4.7$ & 0.69 \\
\hline PPROM haftası (hafta) & $29.6 \pm 2.9$ & $29.4 \pm 2.8$ & 0.75 \\
\hline ASİ (mm) & $76.5 \pm 6.3$ & $78.4 \pm 4.8$ & 0.76 \\
\hline $\begin{array}{l}\text { Ortalama maternal lökosit } \\
\text { (n/ml) }\end{array}$ & $16146 \pm 796$ & $15424 \pm 580$ & 0.46 \\
\hline Antibiyoterapi süresi (gün) & $5.2 \pm 3.1$ & $6.5 \pm 3.8$ & 0.73 \\
\hline $\begin{array}{l}\text { Kortikosteroid ile doğum arası } \\
\text { süre (gün) }\end{array}$ & $5.1 \pm 3.4$ & $7.1 \pm 4.1$ & 0.23 \\
\hline
\end{tabular}

VKİ: Vücut kitle indeksi, PPROM: Preterm premature mebran rüptürü, ASI: Amniyotik sivi indeksi.

Tablo 2: Grupların doğumdaki klinik bulgularının karşılaştırılması.

\begin{tabular}{|l|l|l|l|}
\hline \multicolumn{1}{|c|}{ Değişken } & \multicolumn{1}{|c|}{$\begin{array}{c}\text { Grup 1 } \\
\text { (std veya \%) }\end{array}$} & $\begin{array}{c}\text { Grup 2 } \\
\text { (std veya \%) }\end{array}$ & p \\
\hline $\begin{array}{l}\text { PPROM'dan doğuma } \\
\text { kadar geçen süre (gün) }\end{array}$ & $5.8 \pm 2.1$ & $8.3 \pm 3.5$ & 0.19 \\
\hline Doğum haftası & $30.4 \pm 2.3$ & $30.5 \pm 2.5$ & 0.91 \\
\hline Doğum kilosu (gr) & $1584 \pm 481$ & $1599 \pm 445$ & 0.87 \\
\hline Sezaryen ihtiyac1 & $19(44.1)$ & $37(74)$ & 0.03 \\
\hline Koryoamniyonit gelişimi & $6(13.9)$ & $9(18)$ & 0.39 \\
\hline
\end{tabular}

Grup 1'de tüm hastalar spontan travaya girmiş hastalarken Grup 2'deki hastaların doğum endikasyonlar1: koryoamniyonit (\%18), anhidramniyos (\%12), fetal distress (\%12), abruptio plasenta (\%6), umblikal kord prolapsusu (\%4) ve gebeliğin 34 . haftaya ulaşması (\%22) olarak belirlendi.

PPROM oluşan zamandan doğuma kadar geçen süre Grup 2'de Grup 1'e göre ortalama $3 \pm 0.8$ gün daha fazlaydı ancak bu fark istatistiksel olarak anlamlı bulunmadı (p:0,19). Ortalama doğum haftasinin Grup 1'de 30.4 \pm 2.3 hafta iken Grup 2 'de $30.5 \pm 2.5$ haftaydı ve bu fark anlamlı değildi (p:0.91). Yine doğum ağırlıkları açısından iki Grup arasında anlamlı fark tespit edilmedi. Takip sürecinde Grup 1'de 6 (\%13.9) hastada klinik koryoamniyonit gelişirken bu sayı Grup 2'de 9 (\%18) olarak belirlendi ancak bu fark istatistiksel olarak anlamlı değildi. Doğum şekilleri karşılaştırıldığında Grup 1 'de yer alan 43 hastanın 19 (\%44.1)'u sezaryen ile doğum yaparken $24(\% 55.9)$ olgu vajinal doğum yapt1. Grup 2'de ise 50 olgunun sadece 13 (\%26)'s1 vajinal doğum yaptı ve 37 (\%74) olguda sezaryen ihtiyacı görüldü ve bu fark iki Grup arasında istatistiksel olarak anlamliydı (p: 0.03).

Yenidoğanların 1 ve 5. dakika APGAR skorları iki Grup arasında kıyaslandığında anlamlı fark bulunmad1 (sirasiyla p:0,86 ve p:0,78). Grup 1'de hastaların \%81.3'ünde YDYBÜ ihtiyacı görülürken bu oran Grup 2'de \%81.1'di ve bu fark anlamlı değildi (p: 0.94).

YDBÜ ihtiyacı olan olguların yoğun bakım ünitesinde kalma süreleri karșılaștırıldığında Grup 2 'de Grup 1'den yaklaşı 8 gün daha fazla olmasina karşın bu fark istatistiksel olarak anlamlı bulunmadı (p:0,40). Grup 1'de 4 (\%9.3) olguda YDYBÜ takibi sırasında exitus gerçekleşirken bu sayı Grup 2'de 3 (\%6) olarak saptandı ancak bu fark anlamlı değildi. Grupların YDBÜ'de takip edildiği süre içinde gelişen morbiditeler açısından karşılatırıldığında Grup 1'de 14 (\%32.5) olguda Grup 2'de ise 17 (\%34) olguda ciddi morbidite geliştiği görüldü. Bu morbiditeler incelendiğinde Grup 1'de 1 olguda pnömoni, 1 olguda pnömotoraks, 11 olguda sepsis izlenirken; Grup 2'de 1 olguda menenjit, 1 olguda nekrozitan enterokolit, 2 olguda pnömoni, 12 olguda sepsis, 1 olguda intraventriküler hemoraji geliştiği görüldü. Morbiditeler açısından iki Grup arasında anlamlı fark bulunmadi (p:0,66). Olguların neonatal sonuçlar1 Tablo-3'te özetlenmiştir. Mortalite üzerine latent sürenin etkisine bakıldığında gruplar arasında exitus olan olguların latent süreleri arasındaki fark anlamlı bulunmadı (p:0,54) ayrica her iki grupta ciddi morbidite gelişen olgulara bakıldığında latent sürenin anlamlı etkisi görülmedi (p:0.67). Latent sürenin neontal sonuçlara etkisi Tablo-4'te gösterilmiştir.

Tablo 3: Grupların neonatal bulgularının karşılaştırılması.

\begin{tabular}{|l|l|l|l|}
\hline \multicolumn{1}{|c|}{ Değişken } & \multicolumn{1}{|c|}{$\begin{array}{c}\text { Grup 1 } \\
\text { (std veya \%) }\end{array}$} & $\begin{array}{c}\text { Grup 2 } \\
\text { (std veya \%) }\end{array}$ & \multicolumn{1}{c|}{$\mathrm{p}$} \\
\hline Birinci dakika APGAR & $6.8 \pm 1.5$ & $6.1 \pm 2.1$ & 0.86 \\
\hline Beşinci dakika APGAR & $8.3 \pm 1.1$ & $8.1 \pm 1.2$ & 0.78 \\
\hline YDYBÜ ihtiyacı & $35(81.3)$ & $43(81.1)$ & 0.94 \\
\hline YDYBÜ yatış süresi & $28.3 \pm 5.3$ & $36 \pm 7.1$ & 0.41 \\
\hline Mortalite & $4(9.3)$ & $3(6)$ & 0.54 \\
\hline Ciddi morbidite & $14(32.5)$ & $17(34)$ & 0.87 \\
\hline
\end{tabular}

YDYBÜ: Yenidoğan yoğun bakım ünitesi.

Tablo 4: Gruplar arasında PPROM tarihinden doğuma kadar geçen latent sürenin mortalite ve morbidite gelișimine etkisinin karş1laștırılmasi.

\begin{tabular}{|l|l|l|l|}
\hline \multicolumn{1}{|c|}{ Değişken } & \multicolumn{1}{c|}{ Grup 1 } & \multicolumn{1}{c|}{ Grup 2 } & \multicolumn{1}{c|}{ p } \\
\hline Mortalite & $3.8 \pm 2.1$ & $6.8 \pm 3.3$ & 0.54 \\
\hline Ciddi morbidite & $4.8 \pm 3.1$ & $5.1 \pm 3.9$ & 0.67 \\
\hline
\end{tabular}

\section{TARTIŞMA}

Preterm doğumun önemli bir kısmından sorumlu olan PPROM, günümüzdeki gelişmelere rağmen halen önlenebilir değildir ve bu sebeple prematüritenin getirdiği mortalite ve morbiditenin en önemli sebeplerindendir. PPROM olgularına ideal yaklaşım konusunda kesin bir fikir birliği yoktur ancak birçok kılavuz 34 gebelik haftasına kadar takip ve izlemi önermektedir $(9,10)$. Fakat buna karşın latent sürenin uzamasının maternal ve fetal olumsuz sonuçlara yol açabileceği de düşünülmektedir. Latent süreyi uzatarak prematüritenin getireceği komplikasyonları azaltmaya çalışırken, inflamatuar olayların getireceği komplikasyonlar da göz önünde bulundurmak gerekmektedir.

Servikovajinal flora elemanlarını asendan yolla intrauterin kaviteye ulaşması PPROM'un etiyopatogenezinde en çok üstünde durulan mekanizmalardan birisidir. Bakteriyel kollejenazlar ve proteazlar direkt olarak membranı zayıflatabilir veya salgıladıkları mediyatörlerle lokal matriks metalloprotezlarını aktive ederek amniyotik zarın rüptürüne neden olabilirler (12). 
PPROM ile komplike olan olgularda intramniyotik enfeksiyonun siklığı \%4070 arasında degişmektedir ve PPROM ne kadar erken haftada gerçekleştiyse intramniyotik enfeksiyon riski de o kadar yüksektir (13). İntraamniyotik enfeksiyonun maternal ve fetal risklerinden dolayı bu hastalarda antibiyotik kullanımı yaygın kabul gören bir uygulamadır. Kenyon ve ark. 6800 hastayı içeren 22 çalışmayı değerlendirdikleri metaanalizde PPROM olgularında antibiyoterapi ve plaseboyu karşılaştırmişlar ve antibiyotik kullanılan hastalarda koryoamniyonit riskinde $\% 34,48$ saat içinde doğumda $\% 29$, 7 gün içinde doğumda $\% 33$ ve neonatal enfeksiyon sıklığında \%33 azalma saptamışlardır (14). Antibiyotik kullanımına rağmen PPROM olgularında koryoamniyonit sıklığ $1 \% 9-24$ arasında değişmektedir ve latensi süresi uzadıkça koryoamniyonit sıklı̆̆ arttığ1 düşünülmektedir (15). Daglis ve ark. 24-37 hafta arasındaki 319 PPROM hastasını inceledikleri retrospektif çalıșmalarında olguların olguların \%7.5'inde klinik koryoamniyonit geliştiğini bulmuşlar ve koryoamniyonit gelişen olgularda latensi süresinin koryoamniyonit görülmeyenlere göre anlamlı oranda kısa olduğunu göstermişlerdir (16). Frenette ve ark. ise 24 -37 hafta aras1 4329 PPROM ile komplike olmuş gebeliği inceledikleri çalışmalarında koryoamniyonit ve funisit sıklığını tüm olgularda \%9 olarak bulmuşlar ve bu komplikasyonların latensi süresinin uzaması ile ilişkili olmadığını göstermişlerdir (17). Biz de çalışmamızda koryoamniyonit sıklığını Grup 1'de \%13.8, Grup 2'de ise \%18 bulduk ancak bu fark istatistiksel olarak anlamlı değildi ve latensi süresinin uzaması koryoamniyonit riski ile ilişkili bulunmadı.

Major ve ark. 20-36 hafta aras1 756 PPROM ile komplike hasta ile 11240 kontrol grubunu karşılaştırdıkları çalışmalarında PPROM grubunda hastalarin \%9' de, kontrol grubunda ise sadece $\% 0.5$ ' de abruptio plasenta geliştiğini tespit etmişler ve abruptio plasenta riskinin latensi süresi ile ilişkili olmadığını göstermişlerdir. (18). Bir başka retrospektif kohort çalışmasında Ananth ve ark. PPROM gelişen gebelerde abruptio plasenta sıklığını \%2.3 bulmuşlar ve normal popülasyona göre riskin 3.5 kat arttığ1nı belirtmişlerdir (19). Bizim çalışmamızda Grup 2'deki hastaların \%6'da abruptio plasenta gelişti ve bu oran literatürdeki diğer çalışmalarla uyumlu bulundu. Umblikal kord prolapsusu siklığı tüm gebeliklerde \% 0.1-0.2 arasında görülür ve PPROM varllğı risk faktörü kabul edilir (20). Bendix ve arkadaşları PPROM gelişen 234 hastayı değerlendirdikleri retrospektif çalışmalarında olguların \%36'da en az 1 major komplikasyon geliştiğini tespit ettiler. Bu komplikasyonların \%9'unun umblikal kord prolapsusu, \%29'unun ise fetal distress olduğunu belirlemişlerdir (21). Bizim serimizde Grup 2'deki hastaların $2(\% 4)$ 'sinde umblikal kord prolapsusu, $18(\% 36)$ 'inde fetal distress gelişti ve bu nedenle acil doğum kararı alındı.

PPROM'un yenidoğan üzerindeki en önemli etkileri prematürite komplikasyonlarıdır ve riskin asıl belirleyicileri doğum haftas1 ve doğum ağırlığ1dır (22). En sik görülen komplikasyonlar, respiratuar distress sendromu, yenidoğan sepsisi, nekrotizan enterokolit ve yenidoğan retinopatisi olarak sayıla- bilir. Ayrıca PPROM gelişen gebelerin fetüslerinde nörolojik hasar riskinin spontan preterm doğan fetüslere göre daha fazla olduğu görülmüştür. Spinillo ve ark. PPROM'u takiben 24-34 hafta arası doğan 140 yenidoğanla aynı haftalarda spontan preterm eylem sonrası doğan 120 yenidoğanın nörolojik sonuçlarını karşılaştırmışlar ve ciddi nörolojik morbidite riskinin PPROM grubundaki olgularda 5.7 kat fazla görüldüğünü bulmuşlardır ayrıca PPROM sonras1 latensi süresinin uzaması ile riskin arttığ1nı göstermişlerdir (23). Locatelli ve ark. ise 24-34 hafta arası PPROM sonrası doğan 196 yenidoğanın nörolojik bulgularını değerlendirmişler ve olguların $\% 7.6$ 'da beyaz cevher hasarı olduğunu bulmuşlardır. Beyaz cevher hasarı için en önemli risk faktörünün PPROM'un 28 hafta altında gerçekleşmesi olduğunu göstermişlerdir ayrıca latensi süresi ile beyaz cevher hasarı arasında ilişki bulmamışlardır (24). Bizim çalışmamızda intraventriküler hemoraji Grup 1'deki olguların hiçbirinde görülmezken Grup 2 'de bir (\%2) olguda intraventriküler hemoraji gelişti.

PPROM olgularında birçok kılavuz 34 haftada doğum indüksiyonunu önerse de günümüzde ideal doğum haftası ve ekspektan yaklaşımın yararı sorgulanmaktadır. 690 hasta ve 7 çalışmayı içeren Buchanan ve ark. tarafindan yapilan metaanalizde PPROM sonrası ekspektan yaklaşım ve hemen doğum indüksiyonu karşılaştırılmış ve iki Grup arasında ciddi neonatal morbidite ve mortalite aç1sından fark saptanmamıştır. Hemen doğum indüksiyonu yapilan grupta sezaryen ihtiyacı anlamlı oranda daha fazla bulunmuştur (25). Hazem al-Mandeel ve ark. tarafindan yapilan ve 28-34 hafta arasinda PPROM tanisı ile takip edilen gebelerde hemen doğum ile ekspektan yaklaşımın sonuçlarını içeren metaanalizde 488 hasta ve 5 çalışma değerlendirilmiştir. Respiratuar distress sendromu açısından iki Grup arasında anlamlı fark yokken neonatal sepsis ve neonatal ölüm riski hemen doğum yaptırılan grupta daha fazla bulunmuştur ayrica sezaryen ile doğum hemen doğum yaptırılan hastalarda anlam11 oranda daha fazladır. Bu sonuçlara göre yazarlar bu hastalarda ekspektan yaklaşımın uygun yönetim şekli olduğunu belirtmişlerdir (26). Bizim çalışmamızda da ekspektan yaklaşım sonrası spontan travaya giren hastalar ile maternal veya fetal endikasyonlar nedeniyle doğum indüksiyonu yapılan olgular karşılaştırıldı ve her iki Grup arasında neonatal mortalite ve ciddi morbidite riskinde anlamlı bir fark saptanmadı ancak doğum indüksiyonu gereken grupta sezaryen ile doğum anlamlı oranda daha fazla bulundu.

Pasquier ve arkadaşlarının 24-34 hafta aras1 472 PPROM olgusunda spontan travaya giren olgular ve doğum indüksiyonu yapılan olguların neonatal sonuçlarını karşılaştırdığ mize çok merkezli bir çalışmada latent süresinin 14 günden fazla olduğu olgularda dahi latent süresnin neonatal sonuçlara anlamlı bir yararının olmadığı gösterilmiş ve elektif indüksiyon yapılan grupta ciddi nörolojik morbidite anlamlı oranda daha az bulunmuştur. PPROM'un gerçekleştiği hafta ne kadar ileri ise neonatal komplikasyonların o kadar az görüldüğü gösterilmiştir (27). 
Frenette ve ark. yaptığ 1 çalışmada ise 24-37 hafta aras1 4329 PPROM olgusu incelenmiş ve latent sürenin 48 saati geçtiği olgularda latent sürenin 24 saatten az olan olgulara göre neonatal morbidite insidansı anlamlı oranda az bulunmuștur ve latent sürenin uzamasının anne veya yenidoğanda enfeksiyon riskini arttırmadığ gösterilmiştir (17). Bizim çalışmamızda da hem neonatal mortalite hem de ciddi neonatal morbidite ile latent süre arasında ilişki gösterilemedi.

Bu çalışmada PPROM ile komplike gebeliklerde maternal veya fetal endikasyonlarla doğum indüksiyonu yapılan hastalarla spontan travaya giren hastalar arasinda koryoamniyonit riski ve neonatal sonuçlar açısından anlamlı bir fark olmadığını ancak indüksiyon grubunda sezaryen ile doğumun anlamlı oranda fazla olduğunu gösterdik ayrıca latent süre ile neonatal morbidite ve mortalite arasinda bir ilişki olmadığı sonucuna vardık. Calıșmamızın zayıf yönleri ise hasta sayısının kısıtlılığ 1 ve retrospektif dizaynı olarak görülmektedir.

\section{SONUC}

PPROM gelişen gebeliklerde maternal ve fetal komplikasyonların riski Doğum indüksiyonu yapılanlarla ekspektan yaklaşım uygulanan hastalar arasında yenidoğan sonuçları arasında anlamlı bir fark yoktur ancak indüksiyon yapılan hastalara sezaryen olasılı̆g 1 artmıştır. Latent sürenin neonatal sonuçlara anlamlı etkisi gösterilmemiştir ve bu hastalarda maternal veya fetal iyilik hali güven verdiği sürece ekspektan yaklaşımın uygun takip yöntemi olduğu sonucuna varılmıştır.

\section{KAYNAKLAR}

1. Mercer BM. Preterm premature rupture of the membranes. Obstet Gynecol 2003;101(1): 178-93

2. Creasy RK. Preterm birth prevention: where are we? A m J Obstet Gynecol 1993;168:1223-30

3. Mathews TJ, MacDorman MF. Infant mortality statistics from the 2005 period linked birht/infant death data set. Natl Vital Stat Rep $2008 ; 57: 1$

4. Asrat T, Lewis DF, Garite TJ, et al. Rate of recurrence of Preterm Pemature Rupture of Membranes in consecutive pregnancies. Am J Obstet Gynecol 1991; 165:1111-1115

5. Scott JR, Disaina J, Hammond CB, Spellacy WN. Danforth's Obstetrics andGynecology. 1994; Seventh Edition:305-316

6. Harger JH, Hsing AW, Tuomala RE, Gibbs RS, Mead PB, Eschenbach DA, et al. Risk factors for preterm premature rupture of fetal membranes: a multicenter case-control study. Am J Obstet Gynecol 1990;163(1 Pt 1):130- 7

7. Mercer BM, Goldenberg RL, Moawad AH et al. The preterm prediction study: Effect of gestational age and cause of preterm birth on subsequent obstetric outcome. National Institute of Child Health and Human Development Maternal-Fetal Medicine Units Network. Am J Obstet Gynecol 1999; 181:1216

8. Kenyon S, Pike K, Jones DR, et al. Childhood outcomes after prescription of antibiotics to pregnant women with preterm rupture of membranes: 7 year-follow up the ORACLE I trial. Lancet 2008; $372: 1310$

9. ACOG Practice Bulletin No. 139: Premature rupture of membranes. Clinical management guidelines for obstetrician gynecologists. Obstet Gynecol 2013;122(4):918-30
10. Royal College of Obstetricians and Gynaecologists. Greentop Guideline No. 44: Preterm Prelabour Rupture of Membranes. London: RCOG; 2010

11. J.-C. Pasquier et al. Neonatal outcomes after elective delivery management of preterm premature rupture of the membranes before 34 weeks'gestation (DOMINOS study) Eu J Obstet Gynecol and Reprod Bio 143 (2009) 18-23.

12. Parry S, Strauss JF: Premature rupture of the fetal membranes. N Engl J Med. 1998; 338:663-670 Yoon BH, Romero R, Moon JB, et al. Clinical significance of intra-amniotic inflammation in patients with preterm labor and intact membranes. Am J Obstet Gynecol 2001; 185:1130.

13. Kenyon S, Boulvain M, Neilson JP. Antibiotics for preterm rupture of membranes Cochrane Database Syst Rev 2013;(12):CD001058.

14. Gunn GC, Mishell DR, Morton DG: Premature rupture of the fetal membranes: a review. Am J Obstet Gynecol. 1970; 106:469-482

15. Themistoklis Dagklis, Stamatios Petousis, Chrysoula Margioula-Siarkou, George Mavromatidis, Ioannis, Kalogiannidis, Nikos Prapas, Apostolos Mamopoulos, and David Rousso. Parameters affecting latency period in PPROM cases: a 10-year experience of a single institution. J Matern Fetal Neonatal Med, 2013; 26(14): 1455-1458

16. Waters TP, Mercer BM. The management of preterm prematüre rupture of the membranes near the limit of fetal viability. Am J Obstet Gynecol 2009;201:230-40

17. Priscilla Frenette, Linda Dodds, B. Anthony Armson, Krista Jangaard. Preterm Prelabour Rupture of Membranes: Effect of Latency on Neonatal and Maternal Outcomes. J Obstet Gynaecol Can 2013;35(8):710-717

18. Major CA, de Veciana M, Lewis DF, Morgan MA. Preterm premature rupture of membranes and abruptio placentae: is there an association between these pregnancy complications? Am J Obstet Gynecol 1995; 172:672

19. Ananth CV, Oyelese Y, Srinivas N, Yeo L, Vintzileos AM. Preterm premature rupture of membranes, intrauterine infection, and oligohydramnios: risk factors for placental abruption. Obstet Gynecol 2004; 104:71-75

20. Behbehani S, Patenaude V, Abenhaim HA. Maternal Risk Factors and Outcomes of Umbilical Cord Prolapse: A Population-Based Study. J Obstet Gynaecol Can 2016; 38:23.

21. J. M. Bendix, H. K. Hegaard, T. Bergholt, J. Langhoff-Roos. Expectant management of PPROM and major complications before planned delivery: A retrospective cohort study. Journal of Obstetrics and Gynaecology, 2015;35:570-577

22. Matthews TJ, MacDorman MF, Thoma ME. Infant Mortality Statistics From the 2013 Period Linked Birth/Infant Death Data Set Natl Vital Stat Rep 2015; 64:1.

23. Spinillo A, Capuzzo E, Stronati M, Ometto A, Orcesi S,Fazzi E. Effect of preterm premature rupture of membraneson neurodevelopmental outcome: follow up at two years of age. Br J Obstet Gynaecol 1995; 102:882

24. Locatelli A, Ghidini A, Paterlini $G$, et al. Gestational age at preterm premature rupture of membranes: a risk factor for neonatal whitematter damage. Am J Obstet Gynecol 2005;193:947-51.

25. Buchanan SL, Crowther CA, Levett KM, Middleton P,Morris J. Planned early birth versus expectant management for women with preterm prelabour rupture of membranes prior to 37 weeks' gestation for improving pregnancy outcome. Cochrane Database of Systematic Reviews 2010,17;(3)

26. Hazem Al-Mandeel, Mohammed Y, Alhindi Reg Sauve. Effects of intentional delivery on maternal and neonatal outcomes in pregnancies with preterm prelabour rupture of membranes between 28 and 34 weeks of gestation: a systematic review and meta-analysis. The Journal of Maternal-Fetal and Neonatal Medicine, 2013; 26(1): 83-89

27. J.C. Pasquier et al. Neonatal outcomes after elective delivery management of preterm premature rupture of the membranes before 34 weeks'gestation (DOMINOS study) Eur J Obstet Gynecol and Reprod Bio 143 (2009) 18-23 